\title{
THE ELECTROCARDIOGRAM IN THE TETRALOGY OF FALLOT
}

\author{
BY \\ ARNOLD WOODS \\ From the Cardiac Department, Guy's Hospital, and the National Heart Hospital \\ Received July 21, 1951
}

The features of the standard limb lead electrocardiogram in the tetralogy of Fallot were described by Baker et al. (1949). In all except the earlier cases at Guy's Hospital unipolar limb and chest leads have also been recorded. The purpose of this paper is to present their characteristics in 52 cases in which the diagnosis was well established. In 15 cases the diagnosis has been confirmed by post-mortem examination: some of these and all the others were operated on by Mr. R. C. Brock with either a systemic-pulmonary anastomosis, a pulmonary valvulotomy, or an infundibular resection, and most were investigated by cardiac catheterization or angiocardiography before operation.

The ages of the patients were $3-10$ years in $32,11-20$ years in 18,24 years in 1 , and 34 years in the last.

All the records were taken with the Sanborn visocardiette direct-writing electrocardiograph. In 38 cases the unipolar leads comprised aVR, aVL, aVF, and V1 to V6, while in the remaining 14 aVL, aVF, V1, V3 and V5 were recorded. In 7 cases leads were also taken to the right of V1.

$P$ Wave. As has already been noted by Baker et al. (1949), tall pointed $P$ waves are a striking feature in the standard leads, especially in lead II (Fig. 1). In these 52 cases PII varied from $1 \mathrm{~mm}$. to $5 \mathrm{~mm}$. in height, with an inversion of $2 \mathrm{~mm}$. in one case. In 35 per cent the height was of $2.5 \mathrm{~mm}$. or more (Table I).

TABLE I

The Height of P in leads II and V1-V3 in 52 Cases of Fallot's Tetralogy

\begin{tabular}{l|c|c|c|c|c|c|c|c|c|c}
\hline & & \multicolumn{7}{c}{ Height (in mm.) } \\
\cline { 2 - 8 } & & $0 \cdot 5$ & 1 & $1 \cdot 5$ & 2 & $2 \cdot 5$ & 3 & 4 & 5 \\
\hline $\begin{array}{l}\text { Number } \\
\text { of cases }\end{array}$ & II & 1 & 6 & 11 & 16 & 7 & 7 & 4 & 0 \\
1 & 4 & 5 & 13 & 12 & 5 & 11 & 1 & 1 \\
\hline
\end{tabular}

The $P$ waves were also more prominent than normal in the unipolar leads, especially from the right side of the chest. In V1 to V3, with the tallest $\mathrm{P}$ generally in V1, the height ranged from 0.5 to $5 \mathrm{~mm}$. In 35 per cent the height was of $2.5 \mathrm{~mm}$. or more (Table I).

In only 25 per cent was $P$ most prominent in V1 to V3, and in a further 25 per cent the height in V1 to V3, was equal to that in II, whilst PII was most prominent in 42 per cent. In 8 per cent $P$ in lead $I$ or aVL was taller than in the other leads.

$P-R$ Interval. In no case was the $\mathrm{P}-\mathrm{R}$ interval prolonged beyond normal limits. The range was from $0 \cdot 12$ to $0 \cdot 18 \mathrm{sec}$., with an average of $0 \cdot 15 \mathrm{sec}$.

QRS Complex. The duration of the QRS complex was within normal limits, 0.05-0.08 sec., in all leads in 50 cases $(96 \%)$. In the remaining 2 cases the duration in V1 and one or more other 
leads was $0 \cdot 10 \mathrm{sec}$. or $0.11 \mathrm{sec}$., suggesting incomplete bundle branch block, although in neither of these was an rsR' pattern present (Fig. 2). There was no example of complete right bundle branch block. In one case there was an rsR' $\mathbf{S}^{\prime}$ complex in V1, but the duration was only $0.07 \mathrm{sec}$.

V1 showed a slurred $R$ or an $r R$ complex (Fig. 3) in 23 cases (44\%), and a $\mathrm{qR}$ in $8(15 \%)$. Of the 23 cases with a slurred $R$ or an rR complex, only 3 were amongst the 15 deaths in the series, while all the 8 cases with a $\mathrm{qR}$ complex were amongst the deaths. V6.

In V6 a qR occurred in 20 cases $(39 \%)$; in 2 a qR was present in all the chest leads from V1 to

Intrinsic Deflection. The intrinsic deflection was measured in 50 cases. In V1 the range of the times of the intrinsic deflection was between 0.01 and $0.07 \mathrm{sec}$., with the majority $(68 \%) 0.04-0.05$ (Table II); 94 per cent were delayed to $0.03 \mathrm{sec}$. or more. There were no cases suggesting complete right bundle branch block, the delay never being greater than $0 \cdot 07$, but in $20(40 \%)$ it was between 0.05 and $0.07 \mathrm{sec}$.

In V6 the range was from 0.01 to 0.04 , with 74 per cent less than 0.03 (Table II).

A further indication of the degree of right ventricular hypertrophy is given by the difference between the intrinsic deflections of V1 and V6; in V6, 96 per cent were either less than $(94 \%)$ or equal to $(2 \%)$ those in V1 (Table III). One of the two exceptions is shown in Fig. 4.

$R$ and $S$ Waves. In the standard leads right axis deviation was present in all but one case (98\%). As noted by Baker et al. (1949), it was of such a degree that right ventricular preponderance was sug- 

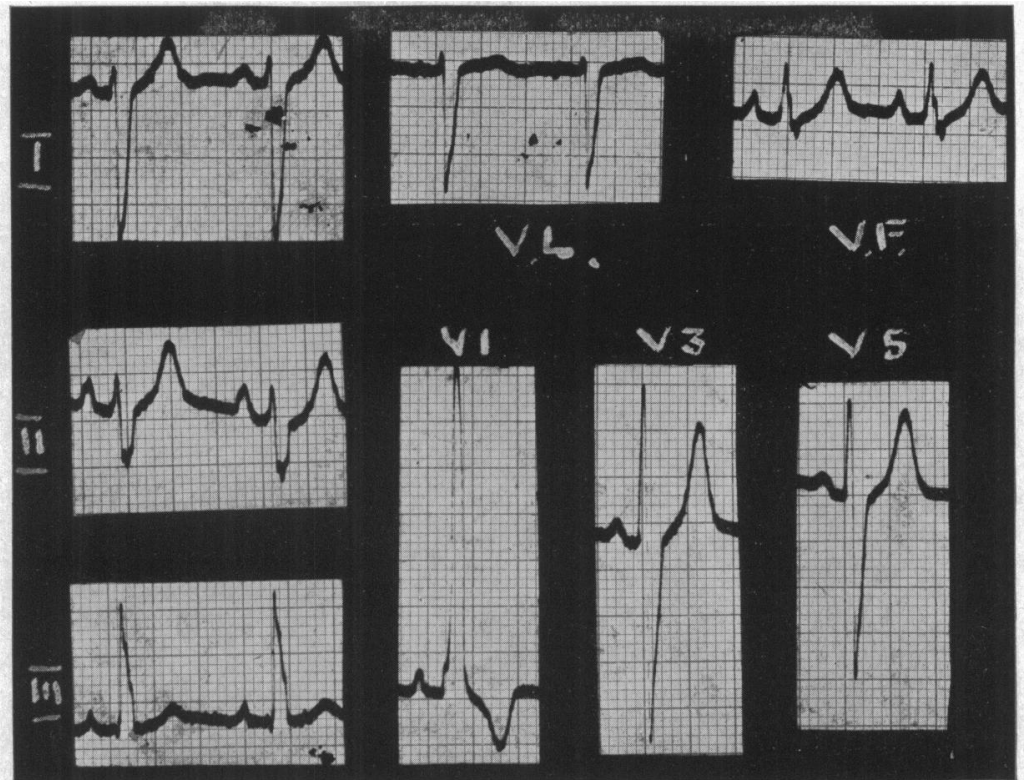

FIG. 2.-A case of Fallot's tetralogy with infundibular stenosis in which $\mathrm{QRS}=0 \cdot 11$ sec. (Case O263).

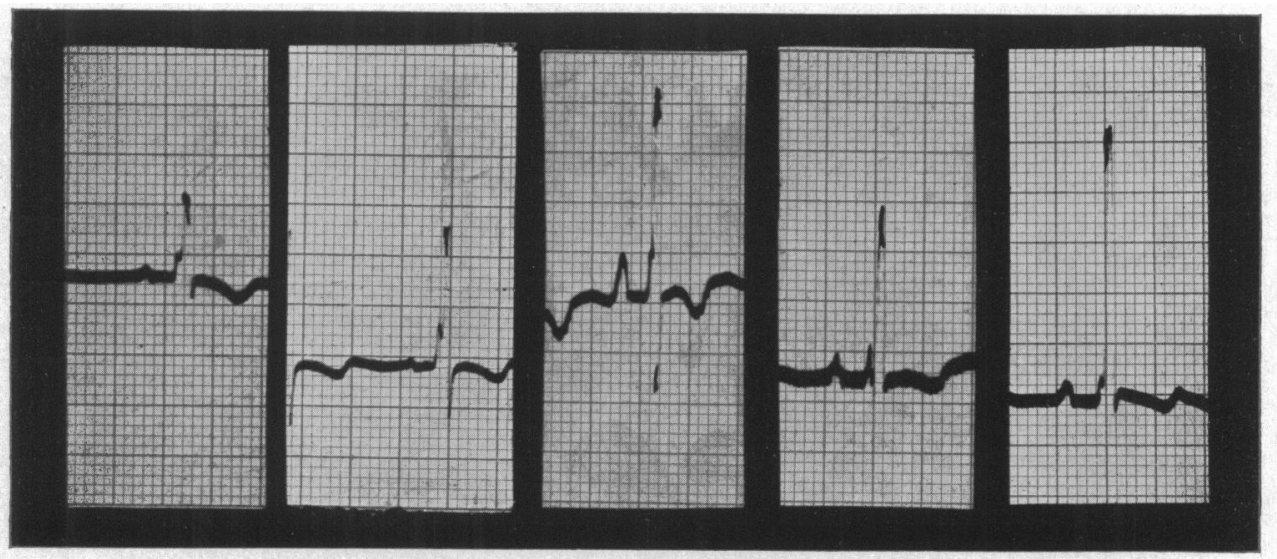

Fig. 3.-Five examples of the slurred $\mathrm{R}$ in V1, which was present in 44 per cent of cases.

TABLE II

The Times of the Intrinsic Deflection in 50 Cases

\begin{tabular}{c|c|c|c|c|c|c|c|c}
\hline & & \multicolumn{7}{|c}{ Intrinsic deflection (in sec.) } \\
\cline { 2 - 9 } & & 0.01 & 0.02 & 0.03 & 0.04 & 0.05 & 0.06 & 0.07 \\
\hline $\begin{array}{c}\text { Number } \\
\text { of } \\
\text { cases }\end{array}$ & $\mathrm{V} 1$ & 1 & 2 & 6 & 21 & 13 & 5 & 2 \\
\hline
\end{tabular}




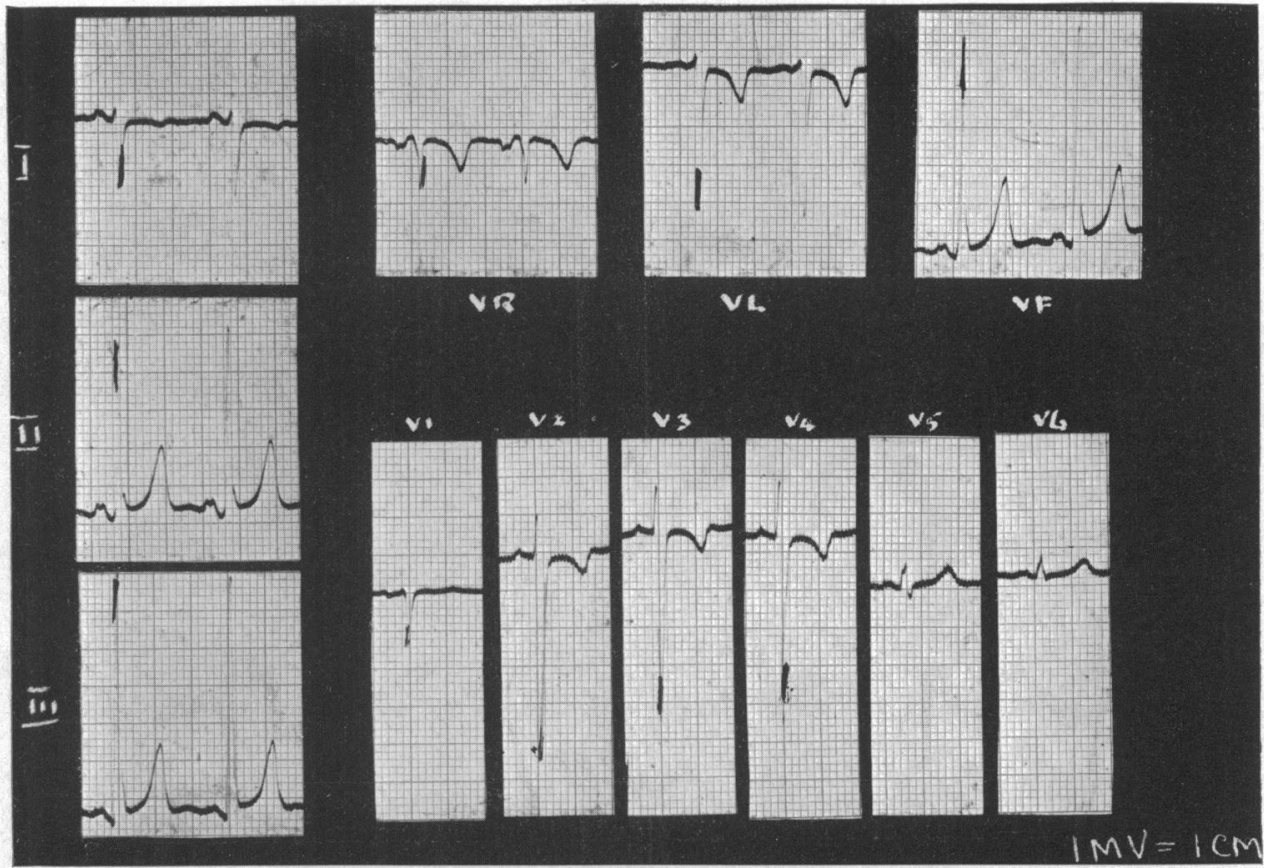

FIG. 4.-An atypical case, in which there was an $\mathrm{rS}$ complex in V1 and the intrinsic deflection of V6 was greater than that of V1. He was thought to have almost, if not quite, complete pulmonary atresia, but there was a pulmonary artery large enough for anastomosis with a successful result (Case 0447).

TABLE III

The Difference Between the Intrinsic Deflections in V1 and V6 in 50 Cases

\begin{tabular}{l|c|c|c|c|c|c|c|c|c}
\hline & \multicolumn{7}{c}{ I.D. in V6-I.D. in V1 (in sec.) } \\
\cline { 2 - 8 } & -0.05 & -0.04 & -0.03 & -0.02 & -0.01 & 0 & +0.01 & +0.02 & +0.03 \\
\cline { 2 - 7 } \\
$\begin{array}{l}\text { Number } \\
\text { of cases }\end{array}$ & 2 & 8 & 11 & 16 & 10 & 1 & 0 & 1 & 1 \\
\hline
\end{tabular}

gested by the standard leads alone. $\mathbf{R}$ was small and $\mathrm{S}$ deep in I, while in III, $\mathbf{R}$ was prominent and $\mathrm{S}$ absent in the majority $(88 \%)$ and small in the rest. In the remaining case the main deflections were all negative, producing the S S S pattern attributed by Goldberger and Schwartz (1945) to backward displacement of the apex in a vertical heart.

In the unipolar limb leads, according to the criteria of Goldberger (1949), findings characteristic of a vertical heart were present in 49 cases $(94 \%)$; in one the position was horizontal and in two intermediate. However, according to Wilson et al. (1944), the electrical position of the heart would have to be regarded as horizontal in 38 cases $(73 \%)$, vertical in $7(13 \%)$, and intermediate in $7(13 \%)$ and this is more in accord with the anatomical positions as assessed radiologically by screening.

In aVL, rS complexes were present in 30 cases, $Q S$ in 13, and qrS in 7, with an $R$ in one and Rs in one; thus the dominant deflection was an $S$ wave in 50 cases $(96 \%)$.

In aVF, qR complexes were found in 21 cases, $R$ alone in 12, Rs in 9, qRs in 6, RS in 2 and QS and $\mathrm{rS}$ in one case each; thus a dominant $\mathrm{R}$ was present in 48 cases $(92 \%)$.

In aVR, which was recorded in 40 cases, the $Q$ wave was less than 25 per cent of the $R$ wave 
TABLE IV

The Size of R AND S IN V1 AND V6 in 52 CASES

\begin{tabular}{l|r|r|r|r|r}
\hline & \multicolumn{5}{|c}{ Size in mm. } \\
\cline { 2 - 5 } & 20 & $10-20$ & $5-9$ & $0 \cdot 5-4$ & 0 \\
\hline R V1 & 22 & 19 & 7 & 4 & - \\
S V1 & 1 & 3 & 6 & 15 & 27 \\
R V6 & 0 & 8 & 17 & 27 & 0 \\
S V6 & 1 & 11 & 12 & 23 & 5 \\
\hline
\end{tabular}

TABLE V

T WaVes in Standard and Unipolar Limb Leads in 52 CaSes (aVR WAS RECORDED IN ONLY 39 CASES)

\begin{tabular}{c|c|c|c|c}
\hline & Positive & Negative & Diphasic & Isoelectric \\
\hline II & 48 & 2 & 1 & 1 \\
II & 50 & 1 & 1 & - \\
III & 31 & 17 & 4 & - \\
aVL & 11 & 38 & -1 & -2 \\
aVF & 47 & 12 & 2 & 1 \\
\hline
\end{tabular}

in 21, while in 6 further cases it was $25-50$ per cent of the $R$ wave; thus in 68 per cent there was a qR pattern typical or suggestive of right ventricular hypertrophy. In the rest normal patterns were found, either $\mathrm{Qr}(15 \%), \mathrm{QR}$ where $\mathrm{Q}$ was $50-100$ per cent of the $\mathrm{R}$ wave $(15 \%)$ or QS $(2 \%)$.

In V1, $R$ was generally tall and $S$ absent or small. In 41 cases $(78 \%) \mathrm{R}$ was $10 \mathrm{~mm}$. or more, while $S$ was less than $5 \mathrm{~mm}$. in $42(81 \%)$ and absent in $27(52 \%)$ (Table IV). In 48 cases (92\%) $R$ was larger than S in V1 in the initial electrocardiogram (Fig. 1). In the other four cases further leads were taken to the right of V1 and in three R was greater than S in V3R; in a subsequent electrocardiogram of one of these cases the true right ventricular hypertrophy picture with $R$ dominance was found only in V4R. Thus, altogether 51 cases $(98 \%)$ showed a dominance of $R$ over $S$, i.e. a reversal of the normal $\mathrm{R} / \mathrm{S}$ ratio, in the right pectoral lead; the remaining case (Fig. 4) will be discussed later.

In V6 there was relative prominence of $\mathrm{S}$, which was $5 \mathrm{~mm}$. or more in 24 cases $(46 \%)$, while $R$ was less than $10 \mathrm{~mm}$. in $45(86 \%)$. S was greater than $R$ in 46 per cent, equal to $R$ in 12 per cent, and smaller in 42 per cent.

$R-S T$ Segment. In 18 cases (35\%) there was R-ST displacement, but usually only of $0.5 \mathrm{~mm}$. in the standard leads and $1 \mathrm{~mm}$. or less in the præcordial leads, and never more than $2 \mathrm{~mm}$. in either.

$T$ Wave. In the standard leads $\mathrm{T}$ was frequently inverted in lead III, but was normally upright in leads I and II.

In the unipolar limb leads $T$ was inverted in all but 2 of the 40 cases in which aVR was recorded. In aVL an upright $\mathrm{T}$ was more than 3 times as common as an inverted $\mathrm{T}$, while in aVF $\mathrm{T}$ was upright in 47 cases $(90 \%)$ (Table V).

In the præcordial leads $\mathrm{T}$ wave inversion was usually present in only $\mathrm{V} 1$ or not at all, but in 5 cases it extended to V2 or V3, in 2 cases to V4 (Fig. 4), and in one case (Fig. 5) across the whole chest to V6 (Table VI).

$U \cdot$ Wave. U waves were found in one or more standard or unipolar leads in 18 cases $(35 \%)$, 
TABLE VI

Extent of T Wave Inversion in Precordial Leads in 52 Cases

\begin{tabular}{c|c|c|c|c|c|c|c}
\hline & Nil & V1 & $\begin{array}{c}\text { To } \\
\text { V2 }\end{array}$ & $\begin{array}{c}\text { To } \\
\text { V3 }\end{array}$ & $\begin{array}{c}\text { To } \\
\text { V4 }\end{array}$ & $\begin{array}{c}\text { To } \\
\text { V5 }\end{array}$ & $\begin{array}{c}\text { To } \\
\text { V6 }\end{array}$ \\
\hline Number of cases & 14 & 30 & 2 & 3 & 2 & 0 & 1 \\
\hline
\end{tabular}

TABLE VII

The Site of the Transition ZoNe in 52 CASes

\begin{tabular}{|c|c|c|c|c|c|c|c|}
\hline Site & .. & V1-2 & V2-3 & V3-4 & V4-5 & V5-6 & $\begin{array}{l}\text { Beyond } \\
\text { V5 or V6 }\end{array}$ \\
\hline Num & of cases & 17 & 7 & 3 & 6 & 4 & 15 \\
\hline
\end{tabular}

including 5 of the deaths. They were usually small and positive, but occasionally they were negative.

Transition Zone. The degree of rotation was variable and the transition zone was found as often to the left as to the right of V3-4 (Table VII). Thus there was frequently moderate or marked clockwise rotation in the longitudinal axis. In one case where there was a transitional type of complex from V6 to V1, similar complexes occurred to the right of the chest as far as V6R, and only in V7R was a dominant $R$ found (Fig. 6).

Post-operative Electrocardiographic Changes. In 33 cases records after as well as before opera-

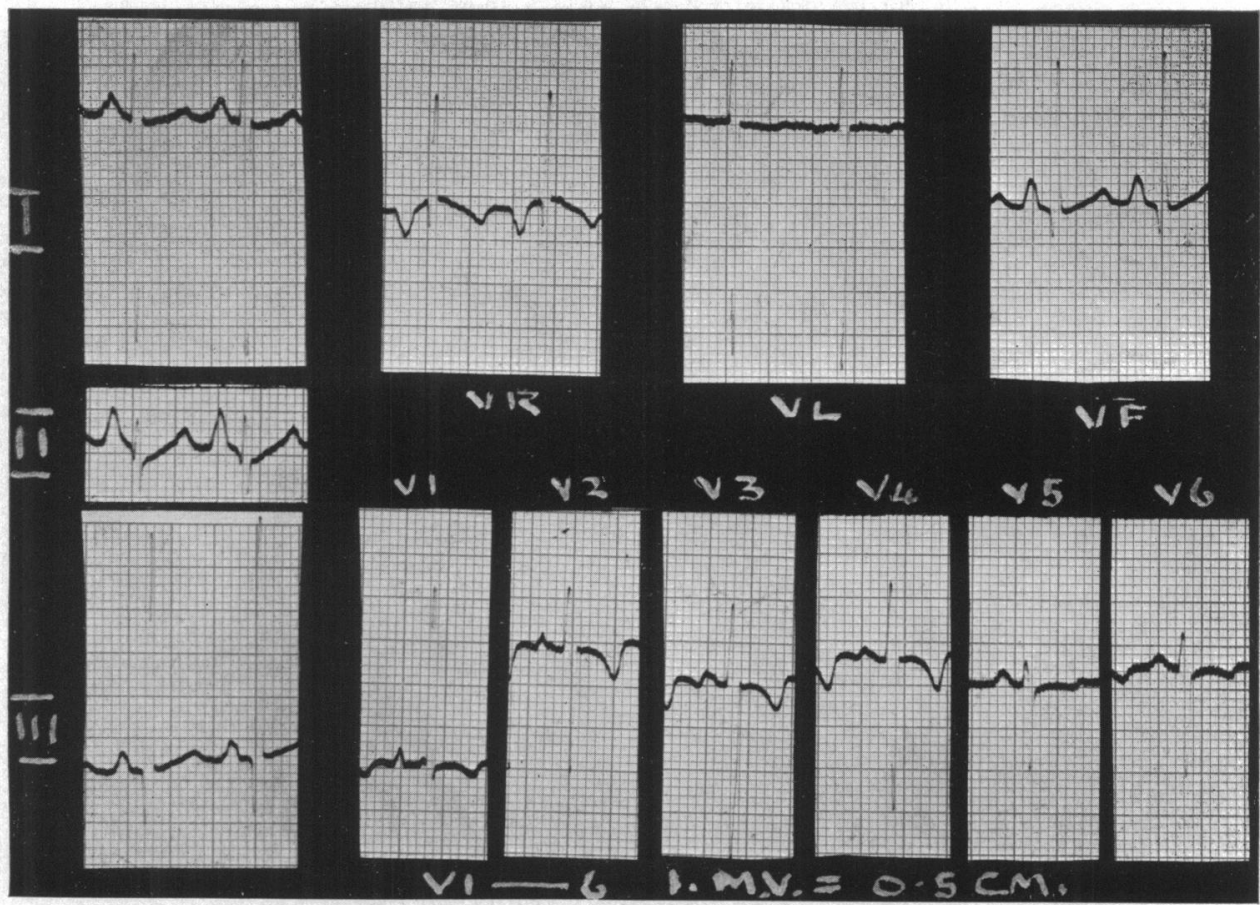

Fig. 5.-T wave inversion is present in all præcordial leads from V1 to V6. Record taken before operation (Case O203). 


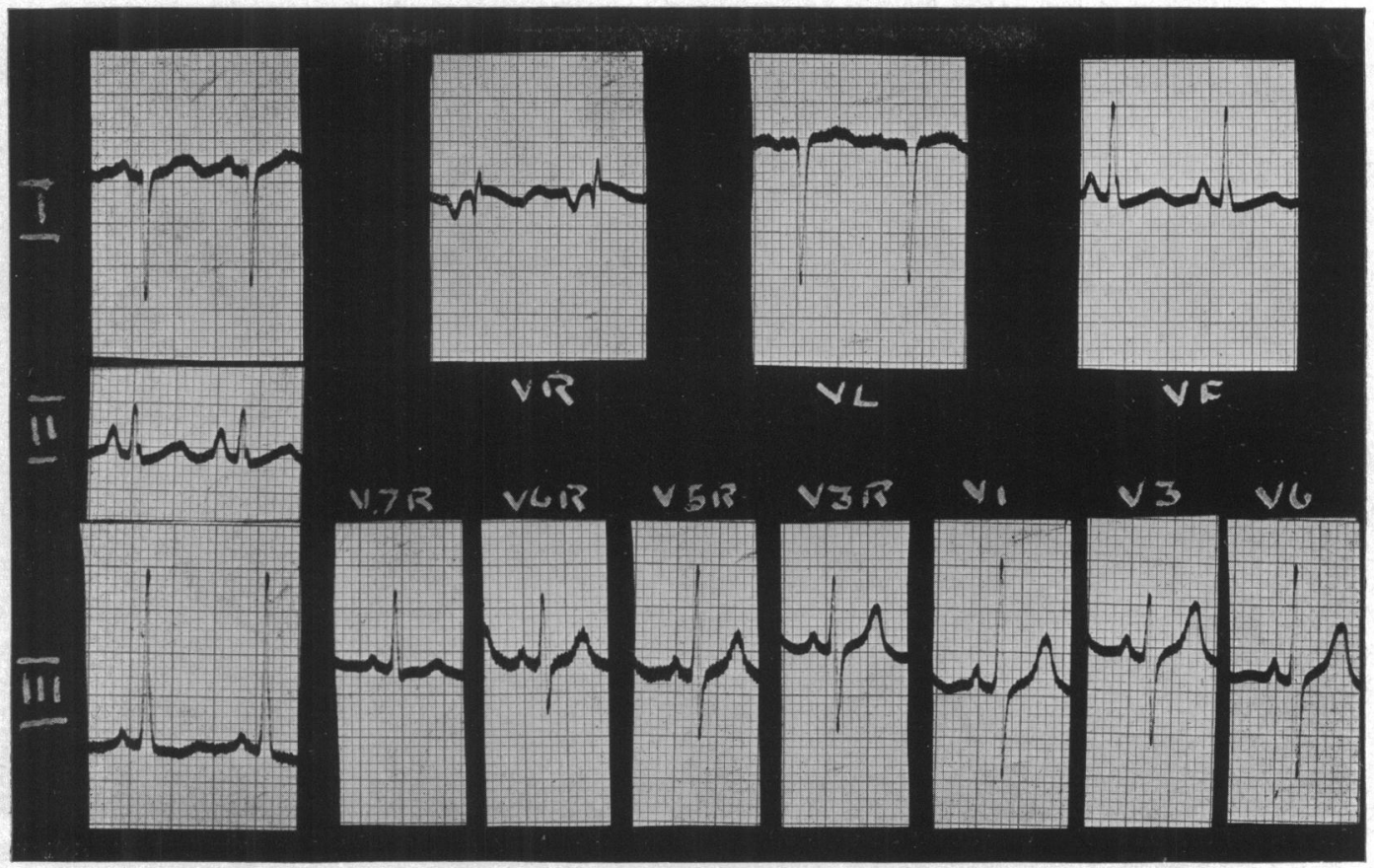

Fig. 6.-A case of Fallot's tetralogy with right ventricular hypertrophy confirmed post mortem in which V7R was the only chest lead with a dominant $R$ (Case O373).

tion were studied; they were taken 1-15 months after the operation. In 17 there was no significant change and in 3 only a slight change due to an alteration in the position of the heart; thus in one case in which the typical Rs pattern was found in V1 before operation, it was only present in V3R afterwards, and this was thought to be due to less marked clockwise rotation.

In 9 cases there were $T$ changes in the præcordal leads. In 8 of these $T$ was inverted only in V1 before operations; in 6 of them T became inverted across to V4, while in the other 2 inversion of $\mathrm{T}$ occurred across V6. These $\mathrm{T}$ wave changes were found only after infundibular resection or pulmonary valvulotomy and were considered to be due to the unavoidable damage to muscle resulting from the use of the ventricular approach; in some there was recovery from the $T$ wave changes in subsequent records. In the last case (Fig. 5) there was $T$ inversion from V1 to V6 before operation but only to V4 following it.

TABLE VIII

Relationship Between the Weight of the Heart and the Thickness of THE Two Ventricles in 7 CASEs Post Mortem, AND the R/S RATIO IN V1

\begin{tabular}{|c|c|c|c|c|}
\hline \multirow[b]{2}{*}{ Case No. } & \multirow{2}{*}{$\begin{array}{l}\text { Weight of } \\
\text { heart } \\
\text { (in grams) }\end{array}$} & \multicolumn{2}{|c|}{ Thickness of } & \multirow[b]{2}{*}{$\begin{array}{l}\mathrm{R} / \mathrm{S} \text { ratio } \\
\text { in } \mathrm{V} 1\end{array}$} \\
\hline & & $\underset{\text { (mm.) }}{\text { R.V. }}$ & $\begin{array}{l}\text { L.V. } \\
\text { (mm.) }\end{array}$ & \\
\hline $\begin{array}{l}\text { O047 } \\
\text { P048 } \\
\text { O246 } \\
\text { O224 } \\
\text { P023 } \\
\text { D.C. } \\
\text { O187 }\end{array}$ & $\begin{array}{r}120 \\
90 \\
\frac{90}{270} \\
100 \\
\frac{220}{2}\end{array}$ & $\begin{array}{r}8 \\
7 \\
15 \\
12 \\
8 \\
9 \\
9\end{array}$ & $\begin{array}{r}4 \\
5 \\
12 \\
10 \\
7 \\
8 \\
10\end{array}$ & $\begin{array}{c}34 / 6 \\
17 / 1 \\
2 / 2 \\
10 / 0 \\
34 / 0 \\
19 / 10 \\
16 / 0\end{array}$ \\
\hline
\end{tabular}


In 4 cases only were there changes in the intrinsic deflections in V1 or V6, and these were slight. In 3 these were increased in V1 from 0.03 or 0.04 to 0.05 , while in one that in V1 was reduced and that in V6 increased by $0.01 \mathrm{sec}$.

Relationship between Electrocardiographic and Post-mortem Measurements. In 7 of the 15 deaths the relative thickness of the ventricles was measured and in all there was evidence of marked right ventricular hypertrophy, thus confirming the electrocardiographic picture. However, there was no correlation between the relative thickness of the two ventricles and the degree of the right ventricular hypertrophy in the electrocardiogram, as measured by either the height of the $R$ wave or the $\mathrm{R} / \mathrm{S}$ ratio in VI (Table VIII). Donzelot et al. (1951) came to a similar conclusion after a study of 10 of their cases.

\section{Discussion}

The criteria for an electrocardiographic diagnosis of right ventricular hypertrophy were described by Myers et al. (1948), and these will be used primarily as a basis for discussion. In this series the electrocardiogram of Fallot's tetralogy fulfilled the majority of these criteria in most cases.

The reversal in the ratio of the amplitudes of $R$ and $S$ in the chest leads was a predominant feature, the changes occurring most frequently in V1 where $R$ was greater than $S$ in 98 per cent. In the remaining case (Fig. 4) an unusual degree of rotation and backward tilting of the apex has resulted in an rS complex in V1.

In V6, S was present in 90 per cent, but in only 46 per cent was it larger than $R$; in some cases the relatively tall $R$ was thought to be due to the marked degree of clockwise rotation found in many cases of Fallot's tetralogy, the dominant $\mathrm{R}$ usually present in V1 sometimes extending as far over to the left side as V6 or V7.

Delay in the onset of the intrinsic deflection to $0.03 \mathrm{sec}$. or more was found in 94 per cent of cases. Sokolow and Lyon (1949), in 60 cases of right ventricular hypertrophy, found a delay to $0.04 \mathrm{sec}$. or more in 70 per cent. Donzelot et al. (1951) found a delay to $0.03 \mathrm{sec}$. or more in 84 per cent in Fallot's tetralogy, and considered the differential index between the intrinsic deflections in V6 and V1 to be the most consistent evidence of right ventricular hypertrophy, for in all 100 cases in their series this figure was negative $(98 \%)$ or zero $(2 \%)$, and this never occurred in normals or cases of left ventricular hypertrophy. The comparable figures in this series were 94 per cent (negative) and 2 per cent (zero). In one case $\mathrm{R} / \mathrm{S}$ in $\mathrm{V} 1$ was $1 / 19$ but the delay in the intrinsic deflection in V1 was 0.04 and the differential index was negative $(-0.03)$, thus affording evidence of right ventricular hypertrophy.

$Q$ in V1 was thought by Myers et al. (1948) to be commonly present in right ventricular hypertrophy, but only a small proportion of their series were cases of Fallot's tetralogy. Donzelot et al. (1951) found it in only 7 per cent in Fallot's tetralogy, and Sodi-Pallares (1950) considered that the qR pattern in V1 is confined almost entirely to the right ventricular hypertrophy due to rheumatic heart disease and to chronic cor pulmonale. In this series a $\mathrm{qR}$ complex was present in 8 cases $(15 \%)$ and all 8 were among the 17 deaths (i.e. $47 \%$ of the deaths). This suggests that $Q$ appears in $\mathrm{V} 1$ in cases with a poor prognosis, and it seems that it might be related to the degree of right ventricular hypertrophy as well as to the degree of rotation; in 6 of the 8 the transition zone is beyond V4, indicating a marked degree of clockwise rotation, although in only 1 is the $T$ wave inversion beyond V2.

The explanation for the $\mathrm{qR}$ pattern in the right chest leads is still under discussion, but the association of the marked rotation with the appearance of the qR pattern in V1 is consistent with the theory advanced by Goldberger (1945) and Kossman et al. (1948), and supported by McGregor (1950), that the pattern of right ventricular hypertrophy is due to rotation of the heart with almost complete reversal of the electrical fields of the two ventricles in the thorax. One patient (Fig. 7) who was at first rejected as a possible case of Fallot's tetralogy on account of apparent left ventricular preponderance, further illustrates this point. On purely clinical grounds the case was considered 


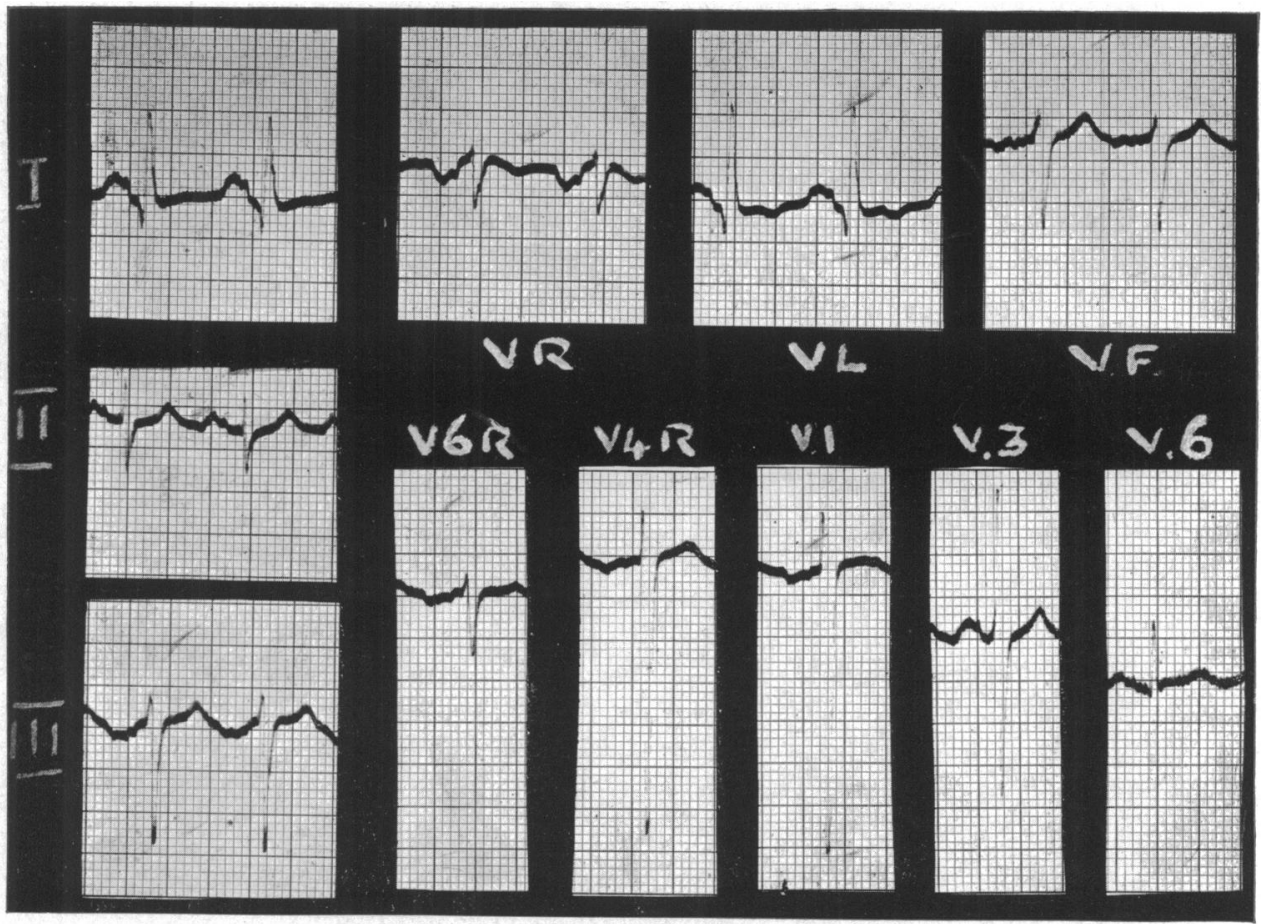

Fig. 7.-Pulmonary stenosis, proved at operation, with misleading electrocardiographic picture suggesting left ventricular hypertrophy (Case O212).

to have Fallot's tetralogy but the picture of left ventricular hypertrophy in the electrocardiogram and on screening made the diagnosis of tricuspid atresia probable (Fig. 7). At operation, however there was evidence of severe pulmonary stenosis, associated with such a degree of counter-clock-wise rotation that the right ventricle and the pulmonary artery was so far over to the right that they could hardly be reached through the usual exposure (Case 22, Brock and Campbell, 1950).

The tendency to inversion of the $T$ wave in $V 1$ and to an upright $T$ wave in $V 6$ was regarded by Myers et al. (1948) to be a further feature of right ventricular hypertrophy. Leatham (1950), in a normal series of adults, found $\mathrm{T}$ inversion in V1 in 19 per cent and an upright $\mathrm{T}$ in V2-V6 in all cases. Sokolow and Lyon (1949), in 60 cases of right ventricular hypertrophy, found $\mathrm{T}$ inversion in V1 in 43 per cent, extending to V2 in 10 per cent and to V3 in 15 per cent. In this series there was $\mathrm{T}$ inversion in $\mathrm{V} 1$ in 38 cases $(73 \%)$, i.e. almost four times as frequently as in a normal series, and it extended beyond V1 in 8 cases (15\%).

The extent of $\mathrm{T}$ wave inversion in the praecordial leads may be of value in differentiating Fallot's tetralogy from severe pulmonary stenosis with a right-to-left inter-atrial shunt. In the latter deep inversion of $T$ often extends far across the left side of the chest (Marquis, 1951); in the former this occurs only rarely, and in this series T was inverted across to V6 in only one case and to V4 in two others $(6 \%)$.

The duration of $Q R S$ in this series was within the normal range in 96 per cent; there was no case of complete right bundle branch block, while in 4 per cent the duration of QRS was prolonged to $0 \cdot 10-0.11 \mathrm{sec}$. due to incomplete right bundle branch block. In 40 per cent the delay of the intrinsic deflection in V1 to 0.05-0.07 sec. suggested the possibility of incomplete right bundle branch block, but the total duration of QRS was not prolonged beyond normal limits. Myers et al. (1948) found incomplete right bundle branch block in 22.5 per cent and complete block in 7.5 per cent of their cases of right ventricular hypertrophy. Donzelot et al. (1951) excluded from their analysis of 100 
cases of Fallot's tetralogy all cases of right bundle branch block, but the incidence for the whole series was 5 per cent (complete) and 11 per cent (incomplete). Thus the incidence of right bundle branch block in this series was less than that described by other authors in comparable series.

$A$ prominent $R$ in $a V R$ is often found in right ventricular hypertrophy. Sokolow and Lyon (1949) considered that an R in aVR of more than $5 \mathrm{~mm}$. indicated right ventricular hypertrophy and found it in 30 per cent. Paul et al. (1951), in an analysis of 101 cases of congenital heart disease found a high $R$ in aVR in 9 of 15 cases with the tetralogy of Fallot $(60 \%)$. A similar incidence $(68 \%)$ was noted for the frequency of an aVR picture typical or suggestive or right ventricular hypertrophy in this series.

A prominent $S$ in V6 was also common, $S$ being $5 \mathrm{~mm}$. or more in 46 per cent and greater than or equal to $\mathrm{R}$ in 58 per cent. However, in no case did the diagnosis of right ventricular hypertrophy depend solely on the prominence of R in aVR or of S in V6.

\section{SUMmaRY AND CONCLUSIONS}

An analysis is presented of the electrocardiographic findings in 52 cases of the tetralogy of Fallot.

Evidence of right ventricular hypertrophy was found in all, and this supported the similar findings by Sokolow and Edgar (1950) in 40 cases, and by Donzelot et al. (1951) in 100 cases.

The standard leads generally showed a very typical picture suggesting a high degree of right ventricular hypertrophy, but the most characteristic and consistent changes were found in the unipolar præcordial leads, especially V1.

TABLE IX

Relative InCidence of Most Characteristic Electrocardiographic Findings in Two Comparable Series of Cases of the Tetralogy of Fallot

\begin{tabular}{|c|c|c|}
\hline & $\begin{array}{l}\text { Donzelot et al. (1951) } \\
\text { (percentage in } 100 \text { cases) }\end{array}$ & $\begin{array}{l}\text { This series } \\
\text { (percentage in } 52 \text { cases) }\end{array}$ \\
\hline $\begin{array}{lll}\text { P wave changes } & . & . . \\
\text { Right axis deviation } & . & \ldots \\
\text { Reversal of R/S ratio } & \because & \\
\text { Delayed intrinsic deflection in } & \text { Vi } \\
\text { Differential index (I.D.) V6-V1 } \\
\text { Tall } R \text { in aVR }\end{array}$ & $\begin{array}{l}80 \\
100 \\
90 \\
84 \\
100 \\
-\end{array}$ & $\begin{array}{l}35 \\
98 \\
98 \\
94 \\
96 \\
68\end{array}$ \\
\hline
\end{tabular}

The most consistent features corresponded closely with those reported by Donzelot et al. (1951) and were reversal of the $\mathrm{R} / \mathrm{S}$ ratio, marked right axis deviation, delay of the intrinsic deflection in V1, and abnormality of the differential index between the intrinsic deflections of V1 and V6 (Table IX).

Taking these changes in rather more detail, abnormally tall pointed $\mathbf{P}$ waves were found in 35 per cent.

Evidence of marked right axis deviation was present in both standard and unipoplar limb leads in 98 per cent. In aVR there was a prominent $R$, indicating right ventricular hypertrophy, in 68 per cent.

The duration of QRS was normal in 96 per cent. There were 2 cases of incomplete, but no case of complete right bundle branch block.

The most consistent changes were found in the right chest lead, especially the reversal of the R/S ratio $(98 \%)$ and the delay of the intrinsic deflection $(94 \%)$, with an abnormal differential index between the intrinsic deflections of V6 and $\mathrm{V} 1(96 \%)$. S was prominent in the left chest leads, but changes in V6 were less striking than those in V1.

A qR pattern in V1 was not common (15\%), but it is suggested that it indicates a severe degree of right ventricular hypertrophy, possibly carrying with it an unfavourable prognosis. 
$\mathrm{T}$ inversion was present in V1 in 73 per cent, but in only 6 per cent did it occur beyond V3. This contrasted. with the deep $\mathrm{T}$ inversion often found far to the left in severe pulmonary stenosis without an overriding aorta.

There were no striking changes in the electrocardiograms, taken before and after operation, except for coronary $\mathrm{T}$ wave changes in cases in which the direct ventricular operative approach was used.

Post-mortem examination confirmed the right ventricular hypertrophy without exception, but no measurable correlation was found between the relative thickness of the two ventricles and the degree of right ventricular hypertrophy in the electrocardiogram.

I wish to express my gratitude to Dr. Maurice Campbell for allowing me to examine the records of his cases, and especially for his advice and encouragement. I should also like to thank Mr. F. H. Muir for his help in making available the many electrocardiograms.

\section{REFERENCES}

Baker, C., Brock, R. C., Campbell, M., and Suzman, S. (1949). Brit. Heart J., 11, 170.

Brock, R. C., and Campbell, M. (1950). Brit Heart J., 12, 377.

Donzelot, E., Metianu, C., Durand, M., Cherchi, A., and Vlad, P. (1951). Arch. Mal. Caur, 44, 97.

Goldberger, E. (1949). Unipolar Lead Electrocardiography. 2nd. ed. Henry Kimpton, London. (1945). Amer. Heart J., 30, 341.

- and Schwartz, S. P. (1945). Amer. Heart J., 29, 62.

Kossman, C. E., Berger, A. R., Brumlik, J., and Briller, S. (1948). Amer. Heart J., 35, 309.

Leatham, A. (1950). Brit. Heart J., 12, 213.

McGregor, M. (1950). Brit. Heart J., 12, 351.

Marquis, R. M. (1951). Brit. Heart J., 13, 89.

Myers, G. B., Klein, H. A., and Stofer, B. E. (1948). Amer. Heart J., 35, 1.

Paul, O., Myers, G. S., and Campbell, J. A. (1951). Circulation, 3, 564.

Sodi-Pallares, D. (1950). Nuevas Bases de la Electrocardiografia. I.N.C. Mexico.

Sokolow, M., and Edgar, A. L. (1950). Amer. Heart J., 40, 232.

, and Lyon, T. P. (1949). Amer. Heart J., 38, 273.

Wilson, F. N., Barker, P. S., Cotrim, N., de Oliveira, R. M., Erlanger, H., Hecht, H., Johnston, F. D., Kossman, C. E. , Rosenbaum, F. F., and Scarsi, R., (1944). Amer. Heart J., 27, 19. 